\title{
Biocompatible ZnS:Mn quantum dots for reactive oxygen generation and detection in aqueous media
}

\author{
Daysi Diaz-Diestra · Juan Beltran-Huarac • Dina P. Bracho-Rincon • \\ José A. González-Feliciano • Carlos I. González • Brad R. Weiner • \\ Gerardo Morell
}

Received: 12 May 2015/Accepted: 19 November 2015/Published online: 30 November 2015

(C) The Author(s) 2015. This article is published with open access at Springerlink.com

\begin{abstract}
We report here the versatility of Mn-doped $\mathrm{ZnS}$ quantum dots (ZnS:Mn QDs) synthesized in aqueous medium for generating reactive oxygen species and for detecting cells. Our experiments provide evidence leading to the elimination of $\mathrm{Cd}$ based cores in $\mathrm{CdSe} / \mathrm{ZnS}$ systems by substitution of Mn-doped ZnS. Advanced electron microscopy, X-ray diffraction, and optical spectroscopy were applied to elucidate the formation, morphology, and dispersion of the products. We study for the first time the ability of ZnS:Mn QDs to act as immobilizing agents for Tyrosinase (Tyr) enzyme. It was found that $\mathrm{ZnS}: \mathrm{Mn}$ QDs show no deactivation of Tyr enzyme, which efficiently catalyzed the hydrogen peroxide $\left(\mathrm{H}_{2} \mathrm{O}_{2}\right)$ oxidation and its eventual reduction $(-0.063 \mathrm{~V}$ vs. $\mathrm{Ag} / \mathrm{AgCl}$ ) on the biosensor surface. The biosensor showed a linear response in the range of $12 \mu \mathrm{mol} / \mathrm{L}-$ $0.1 \mathrm{mmol} / \mathrm{L}$ at low operation potential. Our observations
\end{abstract}

D. Diaz-Diestra $\cdot$ J. Beltran-Huarac .

D. P. Bracho-Rincon · J. A. González-Feliciano ·

C. I. González · B. R. Weiner · G. Morell

Molecular Sciences Research Center, University of Puerto

Rico, San Juan, PR 00926, USA

D. Diaz-Diestra · B. R. Weiner

Department of Chemistry, University of Puerto Rico - Río

Piedras, San Juan, PR 00936, USA

J. Beltran-Huarac $(\bowtie) \cdot$ G. Morell

Department of Physics, University of Puerto Rico - Río

Piedras, San Juan, PR 00936, USA

e-mail: juan.beltran1@upr.edu are explained in terms of a catalase-cycled kinetic mechanism based on the binding of $\mathrm{H}_{2} \mathrm{O}_{2}$ to the axial position of one of the active copper sites of the $o x y$-Tyr during the catalase cycle to produce deoxy-Tyr. A singlet oxygen quantum yield of 0.62 in buffer and 0.54 in water was found when $\mathrm{ZnS}: \mathrm{Mn}$ QDs were employed as a photosensitizer in the presence of a chemical scavenger and a standard dye. These results are consistent with a chemical trapping energy transfer mechanism. Our results also indicate that $\mathrm{ZnS}: \mathrm{Mn}$ QDs are well tolerated by HeLa Cells reaching cell viabilities as high as $88 \%$ at $300 \mu \mathrm{g} / \mathrm{mL}$ of QDs for $24 \mathrm{~h}$ of incubation. The ability of $\mathrm{ZnS}: \mathrm{Mn}$ QDs as luminescent nanoprobes for bioimaging is also discussed.

Keywords ZnS:Mn · Biosensing P Photodynamic therapy · Quantum dots · Singlet oxygen · Tyrosinase

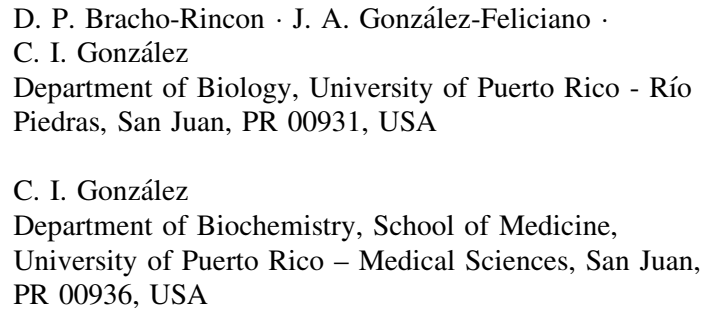




\section{Introduction}

Quantum dots (QDs) are recently being envisioned as potential photosensitizers (PS) for photodynamic therapy (PDT) to treat cancer (Thakor and Gambhir 2013; Allison and Moghissi 2013; Chen et al. 2013), due to their flexible bioconjugation, biological targeting efficiency, high quantum yield (QY), broad absorption with relatively narrow, symmetric emission, and long-term stability (Sotelo-Gonzalez et al. 2013; Zhang et al. 2011; Zhuang et al. 2003; Shen et al. 2012). The availability of QDs whose optical properties can be tuned by size, composition, and doping has brought forth new pathways to produce reactive oxygen species (ROS), in particular singlet oxygen $\left({ }^{1} \mathrm{O}_{2}\right)$, by photochemical methods. As a proof of concept, many QDs have been tested, but a strong focus has been placed on CdSe and CdTe QDs. For instance, $\mathrm{CdSe}$ QDs can be used to sensitize molecular oxygen through a triplet energy transfer mechanism. They can produce a ${ }^{1} \mathrm{O}_{2}$ QY of $\sim 5 \%$ in toluene (cf. $43 \%$ in Pc4 PS used in clinical trials), and their optical properties can be tuned to treat both shallow- and deep-seated tumors (Samia et al. 2003). Shi et al. working with CdTe QDs electrostatically bound to meso-tetra(4-sulfonatophenyl)porphine dihydrochloride (PS) obtained a ${ }^{1} \mathrm{O}_{2}$ QY of ca. $43 \%$ (being $\geq 40 \%$ reported for traditional PSs) (Shi et al. 2006). Nonetheless, they did not fully quantify their results. Still, the cytotoxicity and solubility in water of $\mathrm{Cd}$ based QDs (despite extended efforts to modify their surface) remain a significant concern. In this regard, Hsiech et al. overcoated CdSe cores with $\mathrm{ZnS}$, being then attached to a cyclometalated Ir complex-type sensitizer (Hsieh et al. 2006). Although the ${ }^{1} \mathrm{O}_{2}$ QY in benzene was improved, it was the Ir complex that was directly excited instead of the QDs. It has been reported that $\mathrm{ZnS}$ shells greatly reduce the toxic effects of Cd-based QDs in live cells and provide an improved ${ }^{1} \mathrm{O}_{2}$ QY (as high as $31 \%$ ) (Tsay et al. 2007; Kirchner et al. 2007). Nevertheless, they are still tested in non-aqueous solutions due mainly to the surface chemistry of the core material. We have thus investigated the possibility to omit the use of Cd-based cores and substitute their optical contribution by $\mathrm{Mn}$ doping in ZnS (Bhargava and Gallaguer 1994). Recently, Zhou et al. reported on the sensitizing effect of cysteine-capped Mn-doped ZnS (ZnS:Mn)/Si QDs via the ${ }^{1} \mathrm{O}_{2}$ quenching method (Zhou et al. 2011), but the findings of this exploratory work need further confirmation. The omission of the $\mathrm{Si}$ coating and evaluation of the quantification process of ${ }^{1} \mathrm{O}_{2}$ using ZnS:Mn QDs via photooxidation are still a challenge.

Due to the biocompatibility and high QY (compared to Cd-based QDs) of ZnS:Mn QDs, they are also employed as nanoprobes in order to better understand their main "nano-bio" interaction with cells and bacteria. It has been reported that ZnS:Mn QDs offer improved ability to image single cancer cells and colonies without causing any effect on their metabolic activity and morphology (Mathew et al. 2010; Manzoor et al. 2009). Correlated reports have shown that $\mathrm{ZnS}: \mathrm{Mn}$ capped with different ligands possesses a great capability to image Staphylococcus aureus, exceptional potential to be used for a rapid screening of metal-accumulating Lysinibacillus fusiformis cells, and intrinsic inhibiting effect on the growth of Escherichia coli (Sharma et al. 2010; Sajimol et al. 2013; Kong et al. 2011; Baruah et al. 2012; Li et al. 2004). As a result, ZnS:Mn QDs can be effectively employed to detect cells, especially which are associated to the formation of biofilms. The identification of $P$. aeruginosa cells has aroused a great deal of interest to the scientific community due to their adherence to surfaces (forming biofilms) of nosocomial elements (e.g., catheters, heart valves, and prostheses), and their potential pathogenesis in patients suffering from cystic fibrosis, both constituting a critical health-related issue in hospitals (Cornelis 2008). However, no reports on labeling $P$. aeruginosa cells using biocompatible $\mathrm{ZnS}: \mathrm{Mn}$ QDs have appeared in the literature to date.

ZnS:Mn QDs exhibiting highly active surface areas with an isoelectric point (IEP) of 7.2 are also attractive as innovative matrixes to immobilize enzymes with low IEP, since their interaction is mainly electrostatic. When immobilizing such large biomolecules on solid substrates, it is desirable to retain their electroactive response on the modified electrode surface, and avoid any process related to irreversible denaturalization. Tyrosinase (Tyr) is one of the most used enzymes for the modification of metal electrodes due to its intrinsic enzyme specificity and ability to catalyze the oxidation of many substrates by phenols (Jang et al. 2010). The effective immobilization of Tyr by ZnS:Mn QDs would thereby be a promising alternative given their excellent mechanical, chemical, and thermal stability over prolonged periods (Chauhan et al. 2011). The 
assembly of Tyr/ZnS:Mn-based amperometric biosensors to detect ROS (such as hydrogen peroxide, $\mathrm{H}_{2} \mathrm{O}_{2}$ ) may facilitate a more effective enzymatic binding, improve the properties of the bioactive layer associated with the transducer, and lead to greater efficiency in terms of sensitivity, selectivity, stability, and simplicity (Vreeke et al. 1992; Garguilo et al. 1993). Although some nanostructured immobilizing matrixes have been proposed to enhance the electron transfer rate (Jang et al. 2010; Liu et al. 2011; Zhou et al. 2010; Song et al. 2010); most of them still show low reusability and storage stability, and poor long-term stability due to the large electrochemical prosthetic groups deeply embedded into the structure of the enzyme (Chauhan et al. 2011). In order to increase the electron transfer efficiency of redox enzymes, QDs have recently been proposed due to their inherent large surface-to-volume ratio, high surface reaction activity, and strong absorption ability, which increases the binding site on the electrode surface (Chauhan et al. 2011; Çevik et al. 2012, Xia et al. 2014). Specifically, inexpensive and environmentally benign metal sulfide QDs with sizes similar to those of the working enzymes enable excellent interaction with the active centers buried deep within the protein shells. Recently, Chauhan et al. detected organophosphorus insecticides based on ZnS-immobilized rat brain acetylcholinesterase (Chauhan et al. 2011). In the presence of acetylthiocholine chloride, ZnS QDs promoted electron transfer reactions at low working potential, catalyzed electrochemical oxidation of enzymatically formed thiocholine increasing the detection sensitivity, and exhibited long-term storage stability. Nonetheless, no further reports confirming the immobilizing enzyme characteristics of $\mathrm{ZnS}$ QDs have appeared in the literature. The evaluation of new electron transfer paths employing more stable surfacepassivated ZnS:Mn QDs is still a challenge, for instance, for the detection of $\mathrm{H}_{2} \mathrm{O}_{2}$ at low concentrations.

We report here on the versatility of luminescent water-soluble ZnS:Mn QDs for Tyr immobilization and multiple biological detection. The capability of $\mathrm{ZnS}: \mathrm{Mn}$ QDs to produce ${ }^{1} \mathrm{O}_{2}$ in the presence of 1,3diphenylisobenzofuran (DPBS, ${ }^{1} \mathrm{O}_{2}$ sensor) is presented. The ZnS:Mn QDs are also employed as nanoprobes for imaging $P$. aeruginosa cells, and intended as immobilizing matrixes for Tyr enzyme by crosslinking on modified Pt electrode to detect $\mathrm{H}_{2} \mathrm{O}_{2}$.

\section{Materials and methods}

Synthesis of $\mathrm{ZnS}: \mathrm{Mn}$ quantum dots

Mn-doped ZnS QDs capped with 3-mercaptopropionic acid (MPA, $\geq 99 \%$, Sigma Aldrich, USA) were prepared by an inorganic wet chemical approach reported elsewhere (Beltran-Huarac et al. 2013a, b). Briefly, $1.705 \mathrm{~g}$ of $\mathrm{ZnSO}_{4} \cdot \mathrm{H}_{2} \mathrm{O}(\geq 99.9 \%$, Sigma Aldrich, USA), $0.085 \mathrm{~g} \mathrm{MnSO}_{4} \cdot \mathrm{H}_{2} \mathrm{O}(\geq 99 \%$, Sigma Aldrich, USA), and $2.61 \mathrm{~mL}$ MPA were dissolved into 50-mL three-neck round-bottom flask using high-purity deionized water (HPDW), resulting in a 5 at.\% $\mathrm{Mn}$ doping. The $\mathrm{pH}$ of the mixed solution was adjusted to 11 using $1 \mathrm{M} \mathrm{NaOH}$ (99.99 \%Sigma Aldrich, USA). After argon purging, $50 \mathrm{~mL}$ of $0.2 \mathrm{M}$ aqueous solution of $\mathrm{Na}_{2} \mathrm{~S}$ (Sigma Aldrich, USA) was gradually added. The mixture was stirred at room temperature with a controlled reflux system and then aged for $14 \mathrm{~h}$ at $50{ }^{\circ} \mathrm{C}$. The flocculate was removed from the supernatant by ultracentrifugation, then copiously rinsed with HPDW, and dried at $60{ }^{\circ} \mathrm{C}$ overnight in order to eliminate any remaining by-product and adsorbate. The final products re-dispersed in HPDW rapidly produced a deep orange solution when exposed to UV light, which is a clear indicator of the compound formation, and were employed for further ex situ characterization. ZnS QDs were also prepared following the same recipe for comparison purposes. Peng et al. reported that this synthesis process yields an Mn doping level of 0.380 at.\% when 5 at.\% $\mathrm{Mn}$ is used in the synthesis process as measured by ICP (Peng et al. 2005).

The phase and crystalline structure of QDs were analyzed using an X-Ray Diffractometer (XRD), Model Siemens D5000. Raman spectra were collected via a Jobin-Yvon T64000 spectrometer (resolution $\sim 1 \mathrm{~cm}^{-1}$ ) with Ar-ion laser excitation (514.5 nm), attached to an optical microscope with $80 \times$ resolution. The surface morphology, crystallite size distribution, and elemental composition were studied using a JEOL JEM-2200FS Cs-corrected high-resolution transmission electron microscope (HRTEM) operated at $200 \mathrm{kV}$. A FluoroMax-2 spectrofluorometer was employed to collect the photoluminescence (PL) spectra.

Biosensing measurements

For the biosensor construction, the polycrystalline $\mathrm{Pt}$ electrode surface was mechanically polished with 
alumina paste $(0.05 \mu \mathrm{m})$, washed with HPDW, and rinsed abundantly with anhydrous ethanol $(\geq 99.5 \%$, Sigma Aldrich, USA). The active part of the electrode was a 4-mm-diameter disk, and the other parts were covered with isolating epoxy resin. The as-treated surface was submerged in a $10 \mathrm{mM}$ solution composed of 4-aminothiophenol (ATP, $97 \%$, Sigma Aldrich, USA) diluted in anhydrous ethanol to form a self-assembled monolayer (SAM). Afterwards, $0.2 \mathrm{mg}$ of MPA-capped ZnS:Mn QDs were linked onto SAM surface using a $2 \mathrm{mM}$ solution of N,N'dicyclohexylcarbodiimide (DCC, $60 \mathrm{wt} \%$ in xylenes, Sigma Aldrich, USA) in the presence of N,Ndimethylformamide (DMF, $99.8 \%$, Sigma Aldrich, USA). The Tyr enzyme from mushrooms (low isoelectric point, lyophilized powder, $\geq 1000 \mathrm{unit} / \mathrm{mg}$ solid, Sigma Aldrich, USA) was then immobilized on ZnS:Mn QDs via 1-ethyl-3-(3-dimethylaminopropyl) carbodiimide/ $N$-hydroxysulfosuccinimide (EDC/ Sulfo-NHS, Sigma Aldrich, USA) cross-linking. To do this, the electrode was immersed into a solution of EDC and Sulfo-NHS (1:3 wt. \%) diluted in $1 \mathrm{~mL}$ of phosphate-buffered saline (PBS, $0.1 \mathrm{M}$ and $\mathrm{pH}$ 7.0) for $0.5 \mathrm{~h}$ in order to activate the $\mathrm{ZnS}: \mathrm{Mn}$ QDs. The electrode was then transferred to a solution consisting of $3 \mathrm{mg}$ Tyr enzyme and $2 \mathrm{~mL}$ PBS for $2 \mathrm{~h}$ and kept at $4{ }^{\circ} \mathrm{C}$. The electrode was next rinsed with PBS to remove any unbound enzyme.

Electrochemical responses were analyzed by current voltammetry (CV) and conducted at room temperature using an SP-150 potentiostat/galvanostat and EC-Lab Express software purchased from BioLogic Science Instruments. A three-electrode configuration was used in this study, and the electrodes were purchased from Bioanalytical Systems Inc., USA. The fabricated $\mathrm{Pt} / \mathrm{SAM} / \mathrm{QD} / \mathrm{Tyr}$ was used as the working electrode. $\mathrm{Ag} / \mathrm{AgCl} 3 \mathrm{M} \mathrm{KCl}$ and $\mathrm{Pt}$ wire were used as the reference and auxiliary electrodes, respectively. The voltammograms were collected from -0.4 to $1.2 \mathrm{~V}$ with a scan rate of $50 \mathrm{mV} \mathrm{s}^{-1}$ and at concentrations of $\mathrm{H}_{2} \mathrm{O}_{2}$ ranging from 0 to $100 \mu \mathrm{M}$.

Determination of singlet oxygen

The ${ }^{1} \mathrm{O}_{2}$ generation was verified by photooxidation of 1,3-diphenylisobenzofuran (DPBF, $97 \%$, Sigma Aldrich, USA) and monitored by absorption. A stock solution of capped QDs at $10 \mathrm{mg} / \mathrm{mL}$ and $400 \mu \mathrm{L}$ of $6 \times 10^{-5} \mathrm{M}$ DPBF $\left({ }^{1} \mathrm{O}_{2}\right.$ sensor) in ethanol were gradually mixed in $2 \mathrm{~mL}$ of HPDW and in $2 \mathrm{~mL}$ of buffer separately. The mixture was adequately transferred to a quartz cuvette, then continuous airflow supplied by a gas syringe was progressively added and homogenized by vigorous stirring. The absorbance of the samples was first recorded in the dark using an UV-Vis spectrophotometer (DU 800, Beckman Coulter), and then irradiated with a $532 \mathrm{~nm}$ laser (fluence $\sim 101 \mathrm{~mW} / \mathrm{cm}^{2}$ ) placed $0.4 \mathrm{~m}$ apart. Visible-light excitation was used to avoid the self-oxidation process of DPBF through absorption in the UV region. The absorption spectra were obtained every $2 \mathrm{~s}$ during approximately $16 \mathrm{~s}$. Rose bengal (RB, dye content $95 \%$, Sigma Aldrich, USA) prepared at $1 \times 10^{-5} \mathrm{M}$ was used as control (Beltran-Huarac et al. 2010). All the experiments were done in triplicate.

\section{Imaging $P$. aeruginosa cells}

In order to bind the QDs to the phosphoryl and carboxyl groups present in the cellular wall for bacterial imaging applications, the QDs were positively charged by means of protonated amine groups of chitosan (high purity, $M_{\mathrm{v}} 110-150 \mathrm{kDa}$, Sigma Aldrich, USA) following a similar approach described above by MPA. ${ }^{51}$ For batch cell cultures, the $P$. aeruginosa strain (pellets with a mean assay value of 1.0-9.9 $\times 10^{3}$ CFU purchased from MicroBiologics, USA, 0353E3) with an initial concentration of $5.4 \times 10^{3} \mathrm{CFU} / \mathrm{mL}$ was diluted in $15 \mathrm{~mL}$ of nutrient broth and incubated at $35{ }^{\circ} \mathrm{C}$ for $48 \mathrm{~h}$. The growth curves were obtained by mixing $5 \mathrm{~mL}$ of inoculated $P$. aeruginosa, $5 \mathrm{~mL}$ of QDs $(40 \mathrm{mM})$, and $90 \mathrm{~mL}$ of nutrient broth, and then incubated at $37{ }^{\circ} \mathrm{C}$ under gentle shaking (110 rpm) for $3 \mathrm{~h}$. For negative control, the QDs were replaced by $5 \mathrm{~mL}$ of HPDW. In order to monitor the agglomeration and PL of QDs dispersed in nutrient broth, $5 \mathrm{~mL}$ of QDs $(40 \mathrm{mM})$ were added to $95 \mathrm{~mL}$ of nutrient broth. The absorbance for both the QDs incubated with or without bacteria was monitored and recorded using a UV-Visible spectrophotometer (Helios, $640 \mathrm{~nm}$ ), until reaching the stationary phase in the cell population growth curve. No substantial difference was observed in the log and death phases. After incubation, the cell-QDs suspension was 
washed and precipitated for $30 \mathrm{~min}$. Three $\mathrm{mL}$ of redispersed precipitate and supernatant were then collected for absorbance measurements. Further washing and gentle sonication were applied to the solution to separate the QDs attached to cellular membranes. For confocal microscopy imaging, $200 \mu \mathrm{L}$ of each solution (bacteria-QDs, control and QDs) was added dropwise on a chamber-covered glass cell (Thermo Scientific, Nunc Lab-Tek II) and then excited at $405 \mathrm{~nm}$. The confocal images were recorded using a Zeiss observer Z-1, a laser LSM 510 META using a magnification of $100 \times$, and a $U$ filter set, and were processed through ZEN Lite software developed by Carl Zeiss MicroImaging GmbH.

MTS cell viability assay

The cytotoxicity effects of ZnS:Mn QDs were performed on HeLa cells using the CellTiter $96^{\circledR} \mathrm{AQ}_{\text {ueous }}$ One Solution Cell Proliferation Assay (Promega). HeLa cells were cultured in Eagle's minimum essential medium supplemented with $10 \%$ fetal bovine serum, $100 \mathrm{U} / \mathrm{mL}$ penicillin, $100 \mu \mathrm{g} / \mathrm{mL}$ streptomycin, and $250 \mathrm{ng} / \mathrm{mL}$ amphotericin B (Cellgro) at $37{ }^{\circ} \mathrm{C}$ with $5 \% \mathrm{CO}_{2}$. Cells were plated at a density of ca. $2 \times 10^{4}$ in 96-well plates and grown until reaching 80-90\% confluence. Then, cell culture medium was removed and $100 \mu \mathrm{L}$ of complete medium supplemented with QDs at different concentrations (ranging from 5.2 to $1000 \mu \mathrm{g} / \mathrm{mL}$ ) was added, and three wells with only fresh complete medium were used as a positive control. After 24-h incubation, the medium was removed and a solution of fresh media containing $20 \%$ of CellTiter $96^{\circledR} \mathrm{AQ}_{\text {ueous }}$ One Solution reagent was added. Wells with fresh complete medium and 3-(4,5-dimethylthiazol-2-yl)-5-(3-car-

boxymethoxyphenyl)-2-(4-sulfophenyl)-2H-tetrazolium (MTS) reagent without cells were used as a negative control. Afterwards, cells were incubated at $37{ }^{\circ} \mathrm{C}$ for $30 \mathrm{~min}$. Then, the 96-well plates were centrifuged at $2000 \mathrm{rpm}$ for $10 \mathrm{~min}$. The supernatant was transferred onto a new microplate and the absorbance at $490 \mathrm{~nm}$ was recorded using a Synergy H1 Hybrid Multi-Mode Microplate Reader. The cell viability percentage was ascertained by means of the following equation: \% $=\left[\left(A_{490}\right.\right.$ of QD-treated cells $) /$ $\left(A_{490}\right.$ of untreated cells $\left.)\right] \times 100$. All the experiments were done in triplicate.

\section{Results and discussion}

Characterization of the $\mathrm{ZnS}: \mathrm{Mn}$ quantum dots

The formation and morphology of Mn-doped $\mathrm{ZnS}$ QDs synthesized via a one-pot wet chemical method are depicted in Fig. 1. The XRD and selected area electron diffraction (SAED) patterns show three major diffraction peaks and rings, which are indexed to the diffraction planes of zinc blende $\mathrm{ZnS}$ [(111), (220), and (311)] according to the JCPDS card, File No. 65-0309 and space group (see Fig. 1a). Both techniques confirmed that $\mathrm{ZnS}: \mathrm{Mn}$ crystallized preferentially in the more stable cubic $\mathrm{ZnS}$ phase. No detectable lattice distortion (shift) was observed in the host $\mathrm{ZnS}$ indicative of the successful random substitution of $\mathrm{Mn}^{2+}$ into $\mathrm{Zn}^{2+}$ sites at $5 \mathrm{wt} \% \mathrm{Mn}$ doping. The well-defined peaks and rings found and the absence of parasitic phases and signal of $\mathrm{ZnS}$ wurtzite in the XRD and SAED patterns evidence that ZnS:Mn QDs are of high crystalline quality and purity. The calculated lattice constant of $\mathrm{ZnS}: \mathrm{Mn}$ was $a=0.5384 \pm 0.0007 \mathrm{~nm}$ consistent with its standard value (Beltran-Huarac et al. 2013a, b). The prominent broadening of the XRD diffraction peaks is ascribed to the nanocrystalline nature of the QDs. The average crystallite size was calculated to be $\sim 4 \mathrm{~nm}$ by means of Scherrer's formula.

The microstructure quality of ZnS:Mn QDs was studied by Raman scattering spectroscopy (Fig. 1b). The well-pronounced low-frequency Raman bands observed were simulated using the damped harmonic oscillator phonon model (DHOPM) (Beltran-Huarac et al. 2014). From the simulation, the Raman modes are determined to be at 261 and $342 \mathrm{~cm}^{-1}$, which can be ascribed to the characteristic transverse and longitudinal optical modes of cubic $\mathrm{ZnS}$, respectively (Nilsen 1969). The corresponding fit shows that those bands are red-shifted by $\sim 10 \mathrm{~cm}^{-1}$ and narrow (full width at half maximum, FWHM $\sim 23 \mathrm{~cm}^{-1}$ ) when compared to bulk ZnS (Nilsen 1969), which clearly indicates that the zinc blende $\mathrm{ZnS}$ is under tensile stress as a result of the growth process. The morphology and size distribution of ZnS:Mn QDs were studied by electron microscopy. The HRTEM images depicted in Fig. 1c show well-dispersed QDs with a high degree of crystallinity whose sizes range from 2 to $7 \mathrm{~nm}$. A closer look of representative QDs shows that they are 

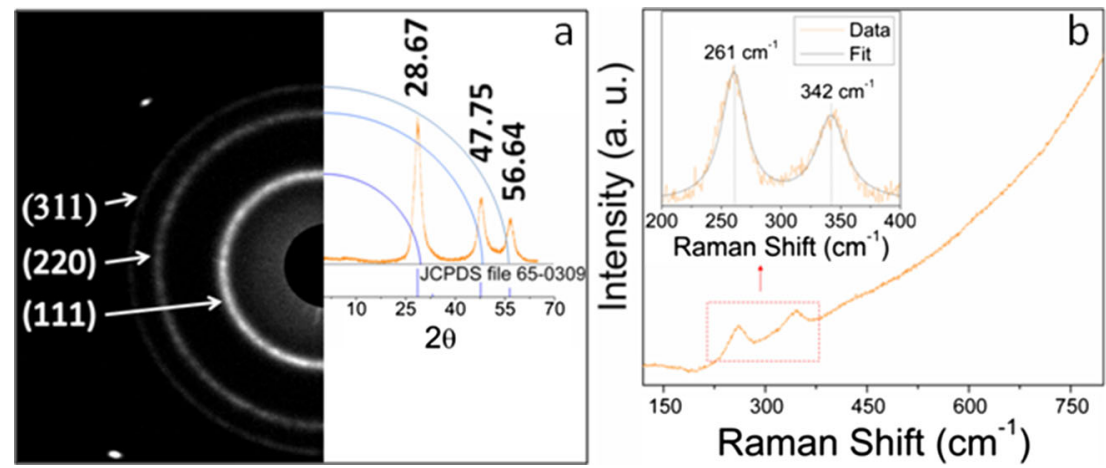

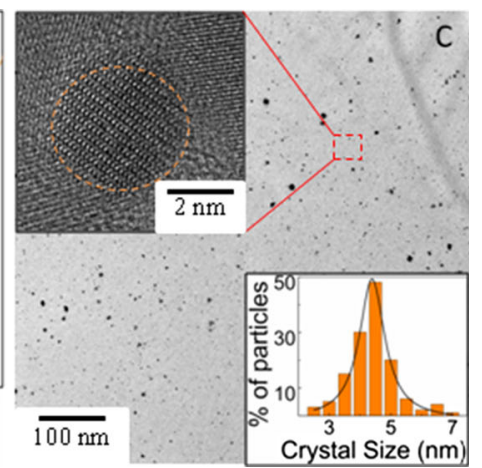

Fig. 1 a XRD and SAED patterns, b Raman spectrum, and c HRTEM image of ZnS:Mn QDs. Inset in (b) shows a close-up of the Raman mode characteristic of $\mathrm{ZnS}: \mathrm{Mn}$. The upper inset in

almost spherical with lattice fringes readily observable and a diameter of $\sim 4 \mathrm{~nm}$. The surfaces of QDs were clean, smooth, and atomically resolved with $d$-spacing of $0.31 \mathrm{~nm}$ corresponding to the major plane (111) of $\mathrm{ZnS}$, consistent with the XRD and SAED analyses. The statistical size distribution (see lower inset of Fig. 1c) obtained by image analysis further confirmed that the average size of QDs was $\sim 4 \mathrm{~nm}$ in accordance with the XRD results. Taken altogether, the $\mathrm{XRD}$, Raman, and HRTEM analyses indicate the formation of narrowly distributed high-quality ZnS:Mn QDs with a zinc blende structure.

Detection of reactive oxygen species (hydrogen peroxide)

The assembly of the amperometric biosensor based on Tyr enzyme immobilized onto ZnS:Mn QDs to detect $\mathrm{H}_{2} \mathrm{O}_{2}$ is depicted in Fig. 2. Prior to the covalent immobilization, the surface of the as-cleaned polycrystalline Pt electrodes was modified using 4-ATP that enables the formation of a $\mathrm{NH}_{2}$-terminated $\mathrm{AM}$, followed by covalent linkage of QDs. The carboxylic acid groups on the surface of QDs were crosslinked to the primary amines of enzyme through an EDCmediated coupling, allowing for a strong covalent immobilization of Tyr onto QDs (see Fig. 2a). Each immobilization step was monitored by $\mathrm{CV}$ via direct detection of the electron transfer of the active ferrocyanide species present in the solution, as shown in Fig. 2b. The voltammogram of the bare Pt electrode shows an anodic peak at $280 \mathrm{mV}$ and a cathodic peak at $220 \mathrm{mV}$ that arises from $\left[\mathrm{Fe}(\mathrm{CN})_{6}\right]^{4-}$ and (c) shows a close-up of an individual QD. The lower inset in (c) shows the statistical size distribution of QDs

$\left[\mathrm{Fe}(\mathrm{CN})_{6}\right]^{3-}$, respectively, and is characteristic of the quasi-reversible one-electron transfer redox behavior of the electroactive species. It was observed that such redox peaks disappear when the 4-ATP electrode modification occurs, which is attributable to the insulating effect produced by the densely packed SAM formation on the electrode surface that hinders the interfacial charge transfer between the ferricyanide ion and the electrode. SAM formation provides the chemical environment necessary to covalently attach MPA-capped QDs onto the electrode. A relative increase in current was detected in Pt/SAM/QDs, which was associated to the electron injection into sub-bandgap states of the metal (Zn,Mn) sulfide (Topoglidis et al. 2001; Boschloo and Fitzmaurice 1999). A decrease in current was observed when Tyr (IEP of $\sim 4.7-5.0$ ) is covalently linked to the QDs. This is due to the enzymatic blockage that is produced on the surface of QDs, thus corroborating both the enzyme deposition and the proposed biosensor assembly (Hernandez-cancel et al. 2015) (see Fig. 2a).

Figure 3 a shows the electrocatalytic response of the biosensor to $\mathrm{H}_{2} \mathrm{O}_{2}$ at concentrations ranging from 0 to $75 \mu \mathrm{M}$ and in the presence of 0.1 M PBS. An enzyme redox peak centered at $\sim 63 \mathrm{mV}$ in the absence of $\mathrm{H}_{2} \mathrm{O}_{2}$ was observed, which signifies that the electroactive prosthetic group of the enzyme is present in close proximity to the modified electrode. An enhancement of the anodic peak current $(\sim 4.61 \mu \mathrm{A})$ was obtained when a $12 \mu \mathrm{M} \mathrm{H}_{2} \mathrm{O}_{2}$ solution was gradually added, indicating that the current response of the biosensor represents the characteristic electrochemical behavior of $\mathrm{H}_{2} \mathrm{O}_{2}$ (Kafi et al. 2008), as 


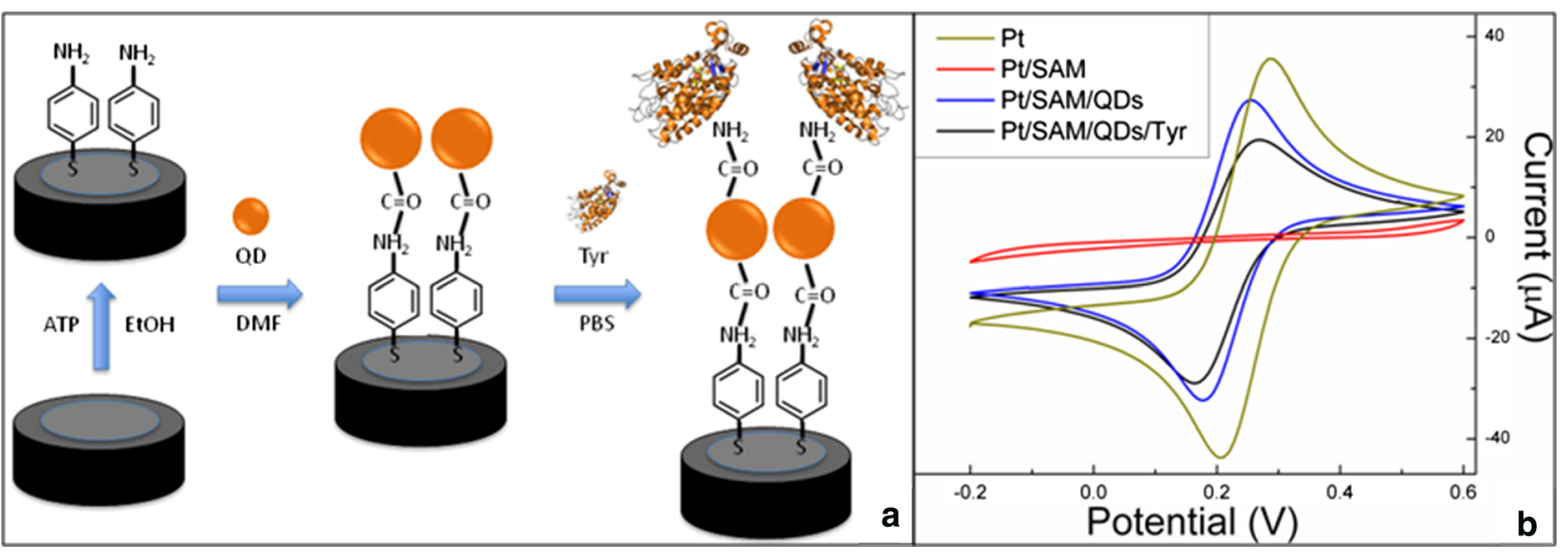

Fig. 2 Stepwise assembly process for the biosensor fabrication. a Main steps of the immobilization of Tyr onto ZnS:Mn QDs and $\mathbf{b}$ their corresponding cyclic voltammograms for the electrochemical detection of $\mathrm{H}_{2} \mathrm{O}_{2}$ in a $3 \mathrm{M} \mathrm{KCl}$ containing $10 \mathrm{mM}$ ferricyanide at a scan rate of $50 \mathrm{mV} \mathrm{s}^{-1}$
Fig. 3 a $\mathrm{H}_{2} \mathrm{O}_{2}-\mathrm{Tyr}$ biosensor in the presence of $0.1 \mathrm{M}$ PBS at $\mathrm{pH} 7.0$ and a scan rate of $50 \mathrm{mV} \mathrm{s}^{-1}$. b Catalase-cycled kinetic mechanism for $\mathrm{H}_{2} \mathrm{O}_{2}$ biosensor based on $\mathrm{ZnS}: \mathrm{Mn} /$ Tyr

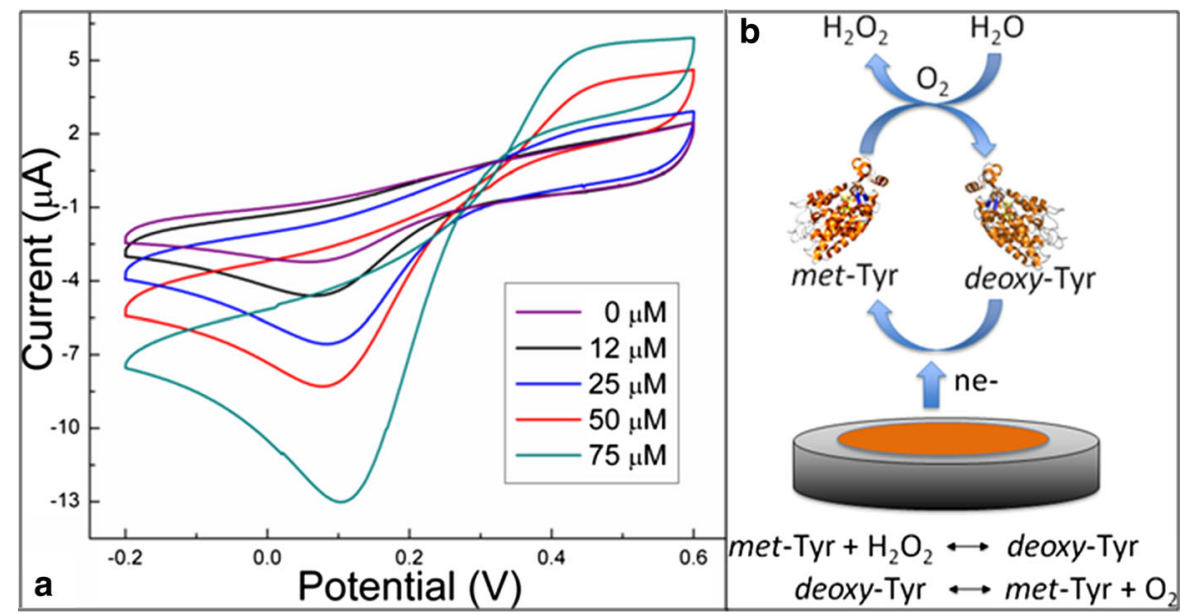

expected. This is due mainly to the catalytic effect of Tyr in the absence of a one-electron donor substrate, which remains active and exhibits an enhanced stability as a result of the effective immobilization of ZnS:Mn QDs. At higher concentrations (as high as $75 \mu \mathrm{M}$ ), a net anodic current of $\sim 13.01 \mu \mathrm{A}$ was detected. This demonstrates that ZnS:Mn-immobilized Tyr exhibits improved catalytic properties in the reduction of $\mathrm{H}_{2} \mathrm{O}_{2}$, and is partially ascribed to the increase of binding sites of the QDs for enzyme loading. It is noteworthy that although the catalytic cycle of Tyr involves $\mathrm{H}_{2} \mathrm{O}_{2}$ consumption and water generation (see Fig. 3b), no inactivation of Tyr was observed up to $100 \mu \mathrm{M}$ of $\mathrm{H}_{2} \mathrm{O}_{2}$ (a current of $\sim 18.18 \mu \mathrm{A})$. This tendency clearly indicates that
$\mathrm{H}_{2} \mathrm{O}_{2}$ is acting as both oxidizing and reducing substrate in solution and is not irreversibly adsorbed on the biosensor surface, i.e., the reaction between $\mathrm{H}_{2} \mathrm{O}_{2}$ and Tyr is a diffusion-controlled process at this scan rate. The catalase activity found in mushroom Tyr/QDs for $\mathrm{H}_{2} \mathrm{O}_{2}$ can be understood in terms of a catalase-cycled kinetic mechanism, as follows. It is known that under anaerobic conditions $\mathrm{Tyr}$ or polyphenol oxidase exhibits two enzymatic species, met-Tyr and deoxy-Tyr, which can initiate the reaction indistinctly. Thus, a $\mathrm{H}_{2} \mathrm{O}_{2}$ molecule of the solution at $\mathrm{pH} 7.0$ can reduce met-Tyr to deoxy-Tyr through the formation of $o x y$-Tyr, which releases oxygen into the medium and is subsequently transformed into deoxyTyr. Then, this is oxidized to met-Tyr upon binding 


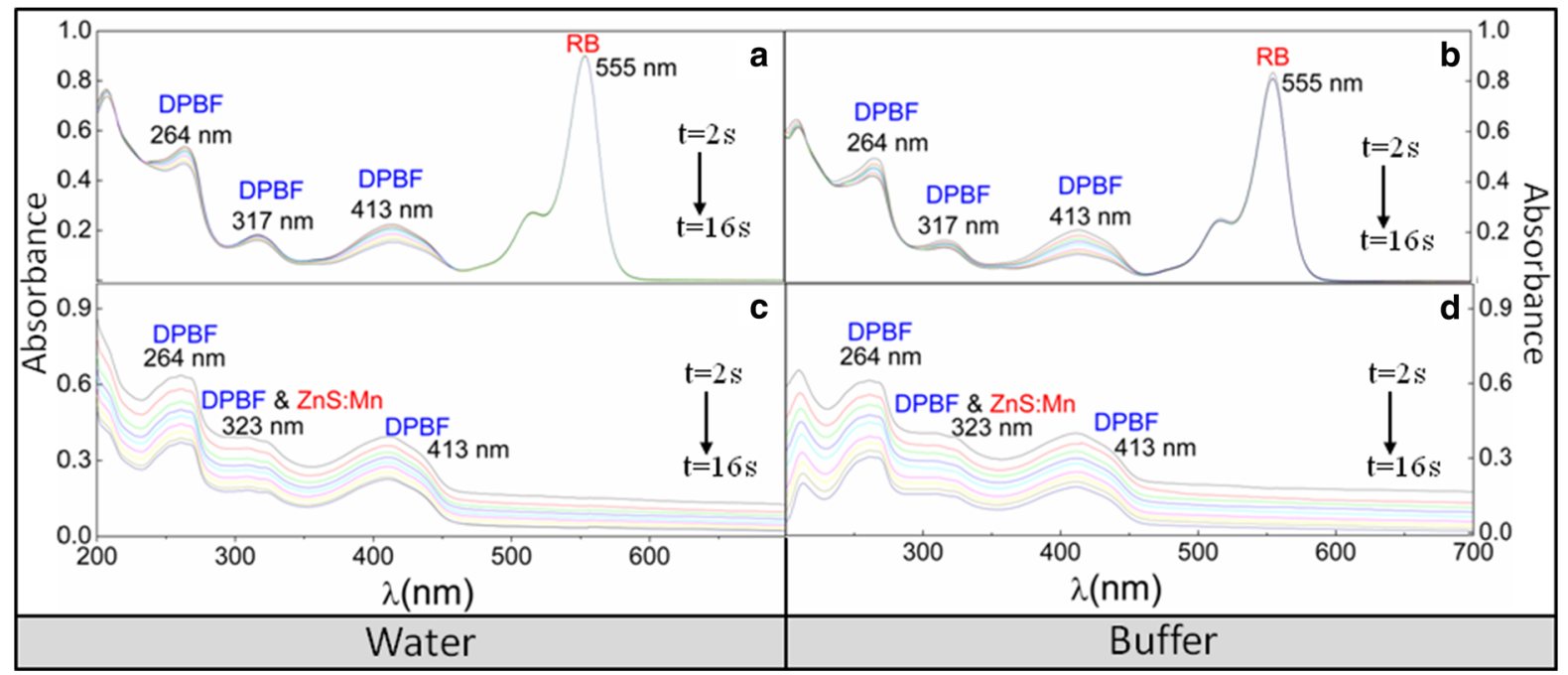

Fig. 4 Absorption spectra of the DPBF oxidation (at $6.0 \times 10^{-5} \mathrm{M}$ ) in the presence of RB (at $\left.1.0 \times 10^{-5} \mathrm{M}\right)$ and $\mathrm{ZnS}$ :Mn QDs $(10 \mathrm{mg} / 10 \mathrm{~mL})$ in air-saturated $\mathbf{a}, \mathbf{c}$ water and $\mathbf{b}, \mathbf{d}$ buffer solutions under vigorous stirring

another $\mathrm{H}_{2} \mathrm{O}_{2}$ molecule (see Fig. 3b). In this context, $\mathrm{H}_{2} \mathrm{O}_{2}$ can be bound to the axial position of one of the active copper atoms of the oxy-Tyr site during the catalase cycle to produce deoxy-Tyr, which correlates well with the recent results obtained for biosensors based on Tyr/ZnO (Rather et al. 2014; Garcia-Molina et al. 2005). This is also consistent with the preparation of binuclear copper active sites of tyrosinase, being able to act on both monophenols and $o$-diphenols in the oxygenated form, oxy-Tyr, whereas the met and deoxy forms need the assistance of oxygen and $\mathrm{H}_{2} \mathrm{O}_{2}$ (Garcia-Molina et al. 2005).

Generation of reactive oxygen species (singlet oxygen)

In the previous discussion, we furnished evidence on the possibility of detecting ROS, such as $\mathrm{H}_{2} \mathrm{O}_{2}$, based on Tyr and ZnS:Mn QDs. We evaluate here the ability of QDs to generate ROS when used as PS, employing both a chemical scavenger (DPBF, a sensor highly sensitive to ${ }^{1} \mathrm{O}_{2}$ ) and a standard PS (RB, a dye with a known ${ }^{1} \mathrm{O}_{2}$ quantum yield) in organic and aqueous media and through a photooxidation approach. To do this, we specifically chose the RB/DPBF pair system because its photo-oxygenation pathway can solely produce ${ }^{1} \mathrm{O}_{2}$ via a Type-II mechanism (BeltranHuarac et al. 2010; Ding et al. 2011). Thus, using $\mathrm{ZnS}: \mathrm{Mn}$ as a PS, excited singlet-state oxygen can be produced by energy transfer, which in turn oxidizes the ground-state substrate. Figure 4 depicts the absorption spectra of the DPBF oxidation photosensitized by RB and ZnS:Mn QDs in water and buffer solution, when exposed to $532 \mathrm{~nm}$ laser irradiation for every $2 \mathrm{~s}$ under vigorous stirring. In order to confirm that the reaction is induced by ${ }^{1} \mathrm{O}_{2}$ instead of a direct interaction between QDs and DPBF, air-saturated solutions were prepared. Oxygen-depleted solutions (via inert gas purge) showed no detectable changes in the absorption spectra. Figure 4a depicts the absorption profile of DPBF $\left(400 \mu \mathrm{L}\right.$ of a $6.0 \times 10^{-5} \mathrm{M}$ solution) in $2 \mathrm{~mL}$ of water in the presence of $\mathrm{RB}$ $\left(1.0 \times 10^{-5} \mathrm{M}\right)$. This spectrum shows the typical absorption band edges of DPBF centered at 264, 317, and $413 \mathrm{~nm}$, and of RB peaking at $555 \mathrm{~nm}$ (BeltranHuarac et al. 2010, 2013a, b; Tuncel et al. 2011). No photooxidation of RB was observed when the samples were exposed to light $(10 \mathrm{~mW})$ for $16 \mathrm{~s}$, as expected. However, the absorption bands of DPBF dropped significantly indicating that the scavenger is being oxidized by singlet oxygen. A more conspicuous photooxidation was seen in the broader absorption band centered at $413 \mathrm{~nm}$, which is used as a reference for the ${ }^{1} \mathrm{O}_{2}$ QY calculation. A similar behavior but with faster reaction rates was observed when a buffer solution is used instead of water (see Fig. 4b). Figure $4 \mathrm{c}$ depicts the absorption profile of DPBF (400 $\mu \mathrm{L}$ of a $6.0 \times 10^{-5} \mathrm{M}$ solution) in $2 \mathrm{~mL}$ of water 


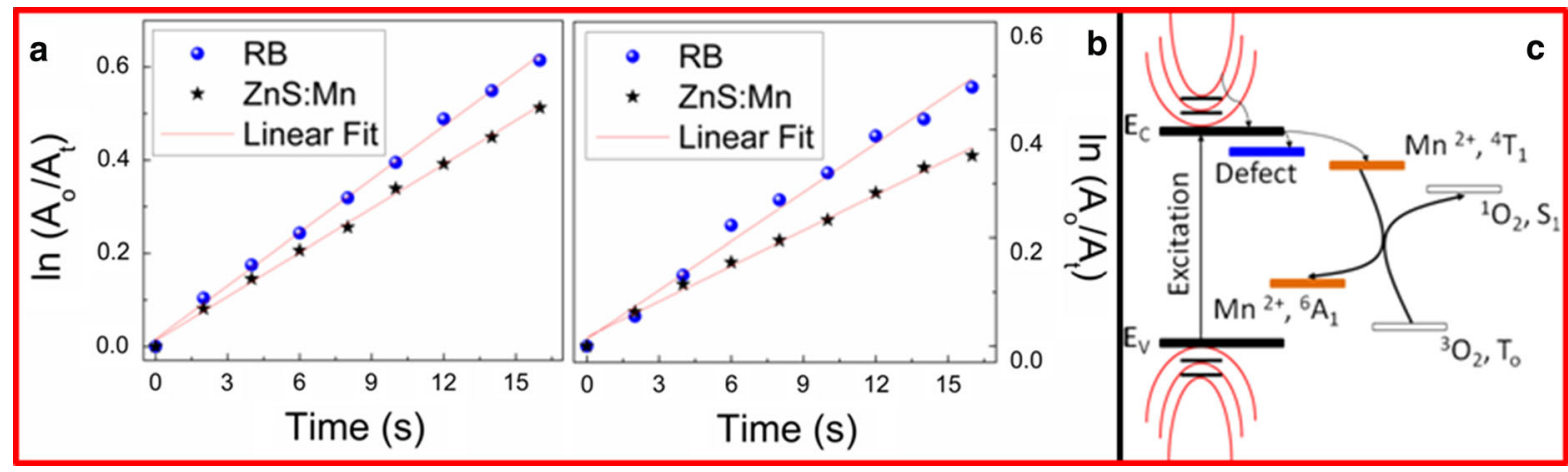

Fig. 5 Decay curves of the $413 \mathrm{~nm}$ absorption band of DPBF $\left(6.0 \times 10^{-5} \mathrm{M}\right)$ induced by singlet oxygen, which are produced by RB and ZnS:Mn QDs at $15 \mu \mathrm{g} / \mathrm{mL}$ in air-saturated a buffer

in the presence of ZnS:Mn QDs (10 mg/10 mL). This spectrum shows the typical absorption band edges of DPBF centered at 264 and $413 \mathrm{~nm}$, and of $\mathrm{ZnS}: \mathrm{Mn}$ peaking at $323 \mathrm{~nm}$ (Beltran-Huarac et al. 2010, 2013a, b). It was difficult to differentiate the absorption band of DPBF at $317 \mathrm{~nm}$ given that the spectral linewidth of the $\mathrm{ZnS}: \mathrm{Mn}$ absorption band was further increased. A more regular DPBF oxidation with larger changes of absorption was also observed, when compared to RB spectra, suggesting that the photoluminescent QDs are multiplet-state photoactive and can be used as a stable, more efficient PS. A similar behavior but with faster reaction rates was observed when the buffer solution is used instead of water (see Fig. 4d). Note that the dependence of the reaction on dissolved $\mathrm{O}_{2}$ indicates that ${ }^{1} \mathrm{O}_{2}$ is generated by the QDs during the photosensitization. No oxidation of DPBF was detected in the absence of light.

In order to calculate the ${ }^{1} \mathrm{O}_{2}$ QY $\left(\Phi_{\Delta}\right)$ of the photoexcited ZnS:Mn QDs in organic and aqueous media, we have expressed the oxidation of DPBF in terms of the decrease of absorbance $(A)$ at $413 \mathrm{~nm}$ as a function of time $\left(\Delta\left(\ln \left[A_{\mathrm{o}} / A_{t}\right] / \Delta(t)\right)\right.$. The profiles of the time-dependent oxidation of DPBF induced by singlet oxygen, obtained by this procedure, are depicted in Fig. 5a, b. It was observed that $\mathrm{ZnS}: \mathrm{Mn}$ shows high reaction rates and a marked linear correlation, i.e., a first-order kinetic reaction, which is a clear indicator that $\mathrm{ZnS}: \mathrm{Mn}$ QDs can yield high ${ }^{1} \mathrm{O}_{2}$ values in both buffer and water. To quantify this observation, we employ a widely validated chemical trapping method (Beltran-Huarac et al. 2010; Nardello et al. 1997; Xiao et al. 2011; Nadhman et al. 2014) that consists in the and $\mathbf{b}$ water. $\mathbf{c}$ Schematic of the chemical trapping mechanism proposed for the generation of singlet oxygen

comparative use of a standard PS of a known $\Phi_{\Delta}$ ( $\Phi_{\Delta \text { standard }}$ ), such as RB, and the slopes determined from the decay curves of a chemical scavenger of ${ }^{1} \mathrm{O}_{2}$, such as DPBF, which irreversibly undergoes a 1,4cycloaddition that is detected as an intensity drop of its absorption band at $413 \mathrm{~nm}$ (Xiao et al. 2011). Thus, the $\Phi_{\Delta}$ (number of ${ }^{1} \mathrm{O}_{2}$ molecules formed per absorbed photon) of ZnS:Mn QDs ( $\left.\Phi_{\Delta \mathrm{ZnS}: \mathrm{Mn}}\right)$ is calculated, as follows (Nardello et al. 1997):

$\Phi_{\Delta \mathrm{ZnS}: \mathrm{Mn}}=\left(\Phi_{\Delta \text { standard }} \cdot k_{\Delta \mathrm{ZnS}: \mathrm{Mn}}\right) / k_{\text {standard }}$,

where $k_{\text {standard }}$ and $k_{\mathrm{ZnS}: M n}$ represent the slopes determined from the decay curves for RB and $\mathrm{ZnS}: \mathrm{Mn}$ QDs, respectively. By introducing the value of $\Phi_{\Delta s-}$ tandard $(\mathrm{RB}=0.76$ ) (Xiao et al. 2011) and the determined slopes, one obtains $\Phi_{\Delta \mathrm{ZnS}: \mathrm{Mn}}=0.62 \pm 0.02$ in buffer and $\Phi_{\Delta \mathrm{ZnS}: \mathrm{Mn}}=0.54 \pm 0.03$ in water. These values are higher than those reported for some semiconductors and metals employed as PSs (see Table 1). Thus, based on our observations, we suspect that the ${ }^{1} \mathrm{O}_{2}$ generation by $\mathrm{ZnS}: \mathrm{Mn}$ QDs in water and buffer solution involves the following (BeltranHuarac et al. 2013; Beltran-Huarac et al. 2010; Xiao et al. 2011; Nadhman et al. 2014; DeRosa and Crutchley 2002): (i) the promotion of electrons toward the conduction band of $\mathrm{ZnS}$ :Mn by light excitation; (ii) nonradiative decay of the photoexcited QDs into a multiplet energy state, ${ }^{4} T_{1}$ (first excited state with spin $3 / 2$ ), due to the internal $\mathrm{Mn}^{2+}$ ion transition; (iii) intersystem crossing of QDs to a long-lived multiplet state, ${ }^{6} A_{1}$ (ground state with spin $5 / 2$ ); (iv) energy transfer from the multiplet state of QDs to the triplet ground state $\left(T_{\mathrm{o}}\right)$ of oxygen $\left({ }^{3} \mathrm{O}_{2}\right)$; and (v) subsequent 
Table 1 Production of ${ }^{1} \mathrm{O}_{2}$ $\Phi_{\Delta}$ for some

semiconductors and metals used as PSs

\begin{tabular}{lll}
\hline Semiconductor/metal & ${ }^{1} \mathrm{O}_{2} \Phi_{\Delta}$ & Reference \\
\hline $\mathrm{CdSe}$ & 0.05 & Samia et al. (2003) \\
$\mathrm{Si} \mathrm{NPs} *$ & 0.11 & Xiao et al. (2011) \\
$\mathrm{ZnO}: \mathrm{Ag}$ & 0.28 & Nadhman et al. (2014) \\
$\mathrm{Fe}_{3} \mathrm{O}_{4} / \mathrm{ZnO}$ & 0.28 & Beltran-Huarac et al. (2010) \\
$\mathrm{CdSe} / \mathrm{CdS} / \mathrm{ZnS} /$ dye & 0.31 & Tsay et al. (2007) \\
$\mathrm{CdTe} /$ dye & 0.43 & Shi et al. (2006) \\
$\mathrm{ZnS}: \mathrm{Mn}$ & $0.62 \pm 0.02$ & Present work \\
\hline
\end{tabular}

* Porous nanoparticles

yield of singlet oxygen $\left({ }^{1} \mathrm{O}_{2}\right)$, which irreversibly reacts with DPBF via a 1,4-cycloaddition yielding an endoperoxide that decomposes in turn to produce o-dibenzoylbenzene. A schematic of these processes is depicted in Fig. 5c. Given that the reaction occurs in solution, we assume that the excited state $\left({ }^{1} \mathrm{O}_{2}\right)$ eventually relaxes back to the ground state $\left({ }^{3} \mathrm{O}_{2}\right)$ via nonradiative deactivation (Hurst and Schuster 1983). In this proposed mechanism, no response of hydroxyl radical and superoxide species was considered since the DPBF is highly selective for ${ }^{1} \mathrm{O}_{2}$. We believe that the powerful visible light supplied by the laser which is used to avoid the self-oxidation process of DPBF (through absorption) and assisted by the $150 \mathrm{~mW}$ continuous ozone-free Xe lamp light (200-800 nm) can induce energy transfer from the particles to the molecular oxygen and DPBF. Taken together, this method provides an efficient pathway to generate ${ }^{1} \mathrm{O}_{2}$, which rapidly reacts with unsaturated carbon-carbon bonds present in DPBF via the energy transfer from the ${ }^{4} T_{1}$ state to molecular oxygen: ${ }^{4} T_{1}$ (PS) $+{ }^{3-}$ $\mathrm{O}_{2} \rightarrow{ }^{6} A_{1}$ (PS) $+{ }^{1} \mathrm{O}_{2}$, wherein $\mathrm{ZnS}:$ Mn QDs act as an efficient PS.

\section{Cytotoxicity and cell imaging}

In the previous discussion, we have accounted for the high ${ }^{1} \mathrm{O}_{2}$ QY of $\mathrm{ZnS}: \mathrm{Mn}$ QDs in terms of a chemical trapping approach, which in turn involves a high PL QY that promotes the ${ }^{4} T_{1}-{ }^{6} A_{1}$ transition. The PL QY of $\mathrm{ZnS}: \mathrm{Mn}$ QDs falls in the range of $13.2-70 \%$ at room temperature with a decay time of a few milliseconds (Shen et al. 2012; Beltran-Huarac et al. 2013a, b; Geszke-Moritz et al. 2011, 2013; Bhargava and Gallaguer 1994). In this section, we further exploit additional PL characteristics of $\mathrm{ZnS}: \mathrm{Mn}$ and evaluate their cytotoxicity in order to employ them as luminescent nano-probes for imaging $P$. aeruginosa cells. The PL spectrum of ZnS:Mn QDs dispersed in water is depicted in Fig. 6a, which shows two emission bands in the visible region. The blue band at $\sim 416 \mathrm{~nm}$ (labeled as defects) is ascribed to $\mathrm{ZnS}$ host, corresponding to the self-activated recombination centers arising from shallow donors and zinc vacancies (Beltran-Huarac et al. 2013a, b), consistent with the photooxidation analysis. The orange emission band at $\sim 598 \mathrm{~nm}$ is due to the internal $\mathrm{Mn}^{2+}$ ion transition, which causes energy transfer from the $s$ $p$ electron-hole pair band states ( $\mathrm{ZnS}$ host) to the $\mathrm{Mn}^{2+}$ ion $d$-electron states (Beltran-Huarac et al. 2013a, b). Both bands in the PL spectrum confirm the homogeneous incorporation of $\mathrm{Mn}^{2+}$ ions into the semiconductor. The optical images of ZnS QDs (blue) and ZnS:Mn QDs (orange) in aqueous solution when exposed to UV light are shown in the inset of Fig. 6a. Prior to evaluating ZnS:Mn QDs as luminescent nanoprobes for bioimaging, we first study their cytotoxic effect on human cervical adenocarcinoma (HeLa) cells. Cell viability was examined through the measurement of cell metabolic activity. The mitochondrial function was measured via MTS viability assay after incubating HeLa cells with different concentrations $(5.2-1000 \mu \mathrm{g} / \mathrm{mL})$ of QDs for $24 \mathrm{~h}$. Viable cells convert MTS tetrazolium into formazan dyes, which can be spectrophotometrically detected (Cory et al. 1991). The cell viability results are depicted in Fig. 6b. It was observed an average of $95 \%$ of viable cells at $5.2 \mu \mathrm{g} / \mathrm{mL}$ of QDs, and $88 \%$ at $300 \mu \mathrm{g} / \mathrm{mL}$. The cell viability slightly decreased until a value of $\sim 68 \%$ at an excessively high concentration $(1000 \mu \mathrm{g} / \mathrm{mL})$. These findings reflect that $\mathrm{ZnS}: \mathrm{Mn}$ QDs are not toxic for human cells and cause a negligible cytotoxicity ( $\sim 32 \%$ of reduction in cell viability) at elevated doses, which are not expected to 


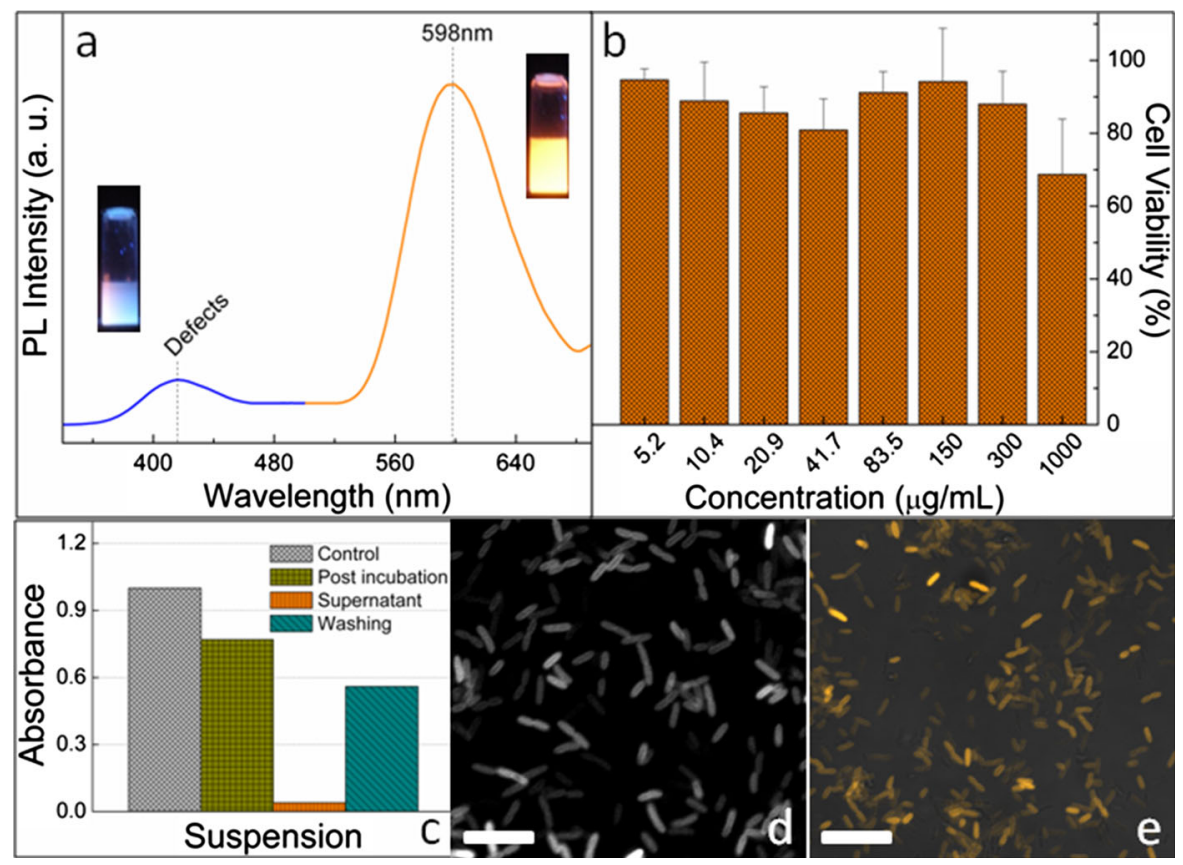

Fig. 6 a PL spectrum of an aqueous solution of ZnS:Mn QDs. The insets show the optical images of $\mathrm{ZnS}$ (blue) and $\mathrm{ZnS}: \mathrm{Mn}$ (orange) QDs dispersed in water as viewed under UV light. b HeLa cell viability in the presence of ZnS:Mn QDs at different concentrations after incubation for $24 \mathrm{~h}$. c Absorbance at $640 \mathrm{~nm}$ of $P$. aeruginosa cells incubated with $5 \mathrm{~mL}$ of an $\mathrm{ZnS}: \mathrm{Mn}$ solution at $40 \mathrm{mM}$. d Representative bright-field image of unlabeled $P$. aeruginosa cells and e confocal microscopy image of ZnS:Mn-labeled P. aeruginosa cells. Scale bars $5 \mu \mathrm{m}$. (Color figure online)

internalization of the $4 \mathrm{~nm} \mathrm{ZnS}: \mathrm{Mn}$ QDs by the cells was confirmed by confocal microscopy, as shown in Fig. 6d, e. It was clearly observed that the QD-labeled cells emit a stronger fluorescent signal (reflected as high-contrast images) when compared to the control (unlabeled cells), revealing the dimension and rod-like morphology characteristic of $P$. aeruginosa strains, which assume a wide range of morphologies and lengths dependent on the growth parameters. The well-defined geometry of the cells suggests that the fluorescence signature was homogeneously distributed throughout the bacterial cell during incubation. No photobleaching effect was observed after a few hours of continuous irradiation exposure, evidencing that the QDs are an ideal alternative to conventional organic dyes that are highly susceptible to light-induced oxidation. Even though the amine groups present in the QDs serve as effective sites for bioconjugation, further studies are needed to fully understand the nature of the molecular associations of the chitosan-capped ZnS:Mn QDs with the P. aeruginosa cells. 


\section{Conclusion}

In summary, we have synthesized ZnS:Mn QDs in aqueous solution at room temperature for multiple types of biological detection and enzyme immobilization. Our findings indicate that $\mathrm{ZnS}: \mathrm{Mn}$-immobilized Tyr biosensor is able to detect not only phenols but also hydrogen peroxide at concentrations below $12 \mu \mathrm{M}$. A correlated synergistic effect was observed between the high catalytic activity of Tyr and the large surface area of QDs, which resulted in an enhanced electrochemical response. Through an indirect assay to monitor the singlet oxygen quantum yield, it was evidenced that ZnS:Mn QDs can be used as an efficient photosensitizer for photodynamic therapy exhibiting a ${ }^{1} \mathrm{O}_{2}$ QY of $0.62 \pm 0.02$ in buffer and $0.54 \pm 0.03$ in water. HeLa cells being exposed to ZnS:Mn QDs for $24 \mathrm{~h}$ show high tolerance reaching cell viabilities as high as $88 \%$ at $300 \mu \mathrm{g} / \mathrm{mL}$. The ability of chitosan-capped $\mathrm{ZnS}: \mathrm{Mn}$ QDs to penetrate microbial cells and serve as luminescent nano-probes makes them suitable to be used as phylogenetic oligonucleotide probes for single-cell detection. Our observations furnish evidence on the possibility to avoid the use of organic acid-stabilized Cd-based systems and substitute their optical contribution with $\mathrm{Mn}$ doping in the $\mathrm{ZnS}$ system for bioimaging, offering a promising biomaterial for expanding the biomedical applications of semiconducting nanocrystals, and bringing forth new arenas to manipulate their theranostic capabilities.

Acknowledgments This work was supported in part by PR NASA EPSCoR (NASA Cooperative Agreement \# NNX13AB22A) and the Institute for Functional Nanomaterials (NSF Grant 1002410). J. Gonzalez-Feliciano and D. Bracho Rincon were supported by the Molecular Sciences Research Center Fellowship. This work was also supported by PES funds from UPR to C. I. Gonzalez. We gratefully acknowledge the valuable assistance of Ms. Griselle Hernández-Cancel in the electrochemical measurements. Special thanks to Dr. Kai Griebenow for the use of his research facilities; Dr. Javier Avalos, Olga Medina, and Rafael Velazquez for the bacteria culture; Dr. Luis A. Rivera for his support in photooxidation measurements; and Dr. Liz Díaz-Vázquez for providing fruitful discussions in biosensor fabrication.

\section{Compliance with ethical standards}

Conflict of interest The authors report no conflict of interest.

Open Access This article is distributed under the terms of the Creative Commons Attribution 4.0 International License (http:// creativecommons.org/licenses/by/4.0/), which permits unrestricted use, distribution, and reproduction in any medium, provided you give appropriate credit to the original author(s) and the source, provide a link to the Creative Commons license, and indicate if changes were made.

\section{References}

Allison RR, Moghissi K (2013) Oncologic photodynamic therapy: clinical strategies that modulate mechanisms of action. Photodiagn Photodyn Ther 10:331-341

Baruah S, Ortinero C, Shipin OV, Dutta J (2012) Manganese doped zinc sulfide quantum dots for detection of Escherichia coli. J Fluoresc 22:403-408

Beltran-Huarac J, Tomar MS, Singh SP, Perales-Perez O, Rivera L, Peña S (2010) Multifunctional $\mathrm{Fe}_{3} \mathrm{O}_{4} / \mathrm{ZnO}$ core-shell nanoparticles for photodynamic therapy. NSTI-Nanotechnol 3:405-408

Beltran-Huarac J, Wang J, Tanaka H, Jadwisienczak WM, Weiner BR, Morell G (2013a) Stability of the Mn photoluminescence in bifunctional $\mathrm{ZnS}: 0.05 \mathrm{Mn}$ nanoparticles. J Appl Phys 114:053106

Beltran-Huarac J, Guinel MJ-F, Weiner BR, Morell G (2013b) Bifunctional $\mathrm{Fe} 3 \mathrm{O} 4 / \mathrm{ZnS}$ : Mn composite nanoparticles. Mater Lett 98:108-111

Beltran-Huarac J, Palomino J, Resto O, Wang J, Jadwisienczak WM, Weiner BR, Morell G (2014) Highly crystalline $\gamma$ MnS nanosaws. RSC Adv 4:38103-38110

Bhargava RN, Gallagher D (1994) Optical properties of manganese-doped nanocrystals of $\mathrm{ZnS}$. Phys Rev Lett 72:416-419

Bhargava RN, Gallagher D, Welker T (1994) Doped nanocrystals of semiconductors-a new class of luminescent materials. J Lumin 60:275-280

Boschloo G, Fitzmaurice D (1999) Spectroelectrochemical investigation of surface states in nanostructured electrodes. J Phys Chem B 103:2228-2231

Çevik E, Şenel M, Baykal A, Abasiyanik MF (2012) A novel amperometric phenol biosensor based on immobilized HRP on poly(glycidylmethacrylate)-grafted iron oxide nanoparticles for the determination of phenol derivatives. Sens Actuat B 173:396-405

Chauhan N, Narang J, Pundir CS (2011) Immobilization of rat brain acetylcholinesterase on $\mathrm{ZnS}$ and poly(indole-5-carboxylic acid) modified $\mathrm{Au}$ electrode for detection of organophosphorus insecticides. Biosens Bioelectron 29:82-88

Chen C, Ahmed I, Fruk L (2013) Reactive oxygen species production by catechol stabilized copper nanoparticles. Nanoscale 5:11610-11614

Cornelis P (2008) Pseudomonas, genomics and molecular biology. Caister Academic Press, Norfok

Cory AH, Owen TC, Barltrop JA, Cory JG (1991) Use of an aqueous soluble tetrazolium/formazan assay for cell growth assays in culture. Cancer Commun 3:207-212

DeRosa MC, Crutchley RJ (2002) Photosensitized singlet oxygen and its applications. Coord Chem Rev 233:351-371

Ding H, Yu H, Dong Y, Tian R, Huang G, Boothman DA, Sumer BD, Gau J (2011) Photoactivation switch from type II to type I reactions by electron-rich micelles for improved 
photodynamic therapy of cancer cells under hypoxia. J Control Release 156:276-280

Garcia-Molina F, Hiner ANP, Fenoll LG, Rodriguez-Lopez JN, Garcia-Ruiz PA, Garcia-Canovas F, Tudela J (2005) Mushroom tyrosinase: catalase activity, inhibition, and suicide inactivation. J Agric Food Chem 53:3702-3709

Garguilo MG, Proctor A, Michael AC (1993) Amperometric sensors for peroxide, choline, and acetylcholine based on electron transfer between horseradish peroxidase and a redox polymer. Anal Chem 65:523-528

Geszke M, Murias M, Balan L, Medjahdi G, Korczynski J, Moritz M, Lulek J, Schneider R (2011) Folic acid-conjugated core/shell $\mathrm{ZnS}: \mathrm{Mn} / \mathrm{ZnS}$ quantum dots as targeted probes for two photon fluorescence imaging of cancer cells. Acta Biomater 7:1327-1338

Geszke-Moritz M, Piotrowska H, Murias M, Balan L, Moritz M, Lulek J, Schneider R (2013) Thioglycerol capped Mndoped $\mathrm{ZnS}$ quantum dot bioconjugates as efficient twophoton fluorescent nano-probes for bioimaging. J Mater Chem B 1:698-706

Hernandez-Cancel G, Suazo-Davila D, Medina-Guzman J, Rosado-Gonzalez M, Diaz-Vazquez LM, Griebenow K (2015) Chemically glycosylation improves the stability of an amperometric horseradish peroxidase biosensor. Anal Chim Acta 854:129-139

Hsieh J, Ho M, Wu P, Chou P, Tsai T, Chi Y (2006) Iridiumcomplex modified CdSe/ZnS quantum dots; a conceptual design for bifunctionality toward imaging and photosensitization. Chem Commun 6:615-617

Hurst JR, Schuster GB (1983) Nonradiative relaxation of singlet oxygen in solution. J Am Chem Soc 105:5756-5760

Jang E, Son KJ, Kim B, Koh W-G (2010) Phenol biosensor on hydrogel microarrays entrapping tyrosinase and quantum dots. Analyst 135:2871-2878

Kafi AKM, Wu G, Chen A (2008) A novel hydrogen peroxide biosensor based on the immobilization of horseradish peroxidase onto Au-modified titanium dioxide nanotube arrays. Biosens Bioelectr 24:566-571

Kirchner C, Liedl T, Kudera S, Pellegrino T, Almudena MJ, Gaub HE, Stölzle S, Fertig N, Parak WJ (2007) Cytotoxicity of colloidal CdSe and CdSe/ZnS nanoparticles. Nano Lett 129:6865-6871

Kong HY, Kim S, Byun J, Hwang C (2011) Differential effects of cysteine and histidine-capped $\mathrm{ZnS}$ : Mn nanocrystals on Escherichia coli and human cells. Bull Korean Chem Soc 32:53-58

Li W, Xie H, Xie Z, Lu Z, Ou J, Chen X, Shen P (2004) Exploring the mechanism of competence development in Escherichia coli using quantum dots as fluorescent probes. J Biochem Biophys Methods 58:59-66

Liu X, Luo L, Ding Y, Xu Y, Li F (2011) Hydrogen peroxide biosensor based on the immobilization of horseradish peroxidase on $\gamma-\mathrm{Al}_{2} \mathrm{O}_{3}$ nanoparticles/chitosan film-modified electrode. J Solid State Electrochem 15:447-453

Manzoor K, Johny S, Thomas D, Setua S, Menon D, Nair S (2009) Bio-conjugated luminescent quantum dots of doped $\mathrm{ZnS}$ : a cyto-friendly system for targeted cancer imaging. Nanotechnology 20:065102

Mathew ME, Mohan JC, Nair SV, Tamura H, Jayakumar R (2010) Folate conjugated carboxymethyl chitosan-manganese doped zinc sulphide nanoparticles for targeted drug delivery and imaging of cancer cells. Carbohydr Polym 80:442-448

Nadhman A, Nazir S, Khan MI, Arooj S, Bakhtiar M, Shahnaz G, Yasinzai M (2014) PEGylated silver doped zinc oxide nanoparticles as novel photosensitizers for photodynamic therapy against Leishmania. Free Radic Biol Med 77:230-238

Nardello V, Brault D, Chavalle J, Aubry J (1997) Measurement of photogenerated singlet oxygen $\left({ }^{1} \mathrm{O}_{2}\left({ }^{1} \Delta_{\mathrm{g}}\right)\right)$ in aqueous solution by specific chemical trapping with sodium 1,3cyclohexadiene-1,4-diethanoate. J Photochem Photobiol B 39:146-155

Nilsen WG (1969) Raman spectrum of cubic ZnS. Phys Rev 82:838-850

Peng WQ, Qu SC, Cong GW, Wang ZG (2005) Concentration effect of $\mathrm{Mn} 2+$ on the photoluminescence of $\mathrm{ZnS}: \mathrm{Mn}$ nanocrystals. J Cryst Growth 279:454-460

Rather JA, Pilehvar S, de Wael K (2014) A graphene oxide amplification platform tagged with tyrosinase zinc oxide quantum dot hybrids for the electrochemical sensing of hydroxylated polychlorobiphenyls. Sens Actuat B 190:612-620

Sajimol AM, Roselin A, Sreevalsa VG, Deepa GD, Sarita GB, Jayalekshmi S (2013) Highly luminescent and biocompatible, L-citrulline-capped ZnS:Mn nanocrystals for rapid screening og metal accumulating Lysinibacillus fusiformis bacteria. Luminescence 28:461-467

Samia ACS, Chen X, Burda C (2003) Semiconductor quantum dots for photodynamic therapy. J Am Chem Soc 125:15736-15737

Sharma M, Singh S, Pandey OP (2010) Excitation induced tunable emission in biocompatible chitosan capped $\mathrm{ZnS}$ nanophosphors. J Appl Phys 107:104319

Shen R, Zeng R, Yin Y, Wan J, Sun Z, Zhao Y, Zhao H (2012) Facile synthesis of Mn-doped $\mathrm{ZnS}$ nanocrystals and determination of critical temperature for lattice diffusion process. J Nanosci Nanotechnol 12:8356-8363

Shi L, Hernandez B, Selke M (2006) Singlet oxygen generation from water-soluble quantum dot-organic dye nanocomposites. J Am Chem Soc 128:6278-6279

Song M, Hwang SW, Whang D (2010) Amperometric hydrogen peroxide biosensor based on a modified gold electrode with silver nanowires. J Appl Electrochem 40:2099-2105

Sotelo-Gonzalez E, Roces L, Garcia-Granda S, Fernandez-Arguelles MT, Costa-Fernandez JM, Sanz Medel A (2013) Influence of $\mathrm{Mn}^{2+}$ concentration on $\mathrm{Mn}^{2+}$-doped $\mathrm{ZnS}$ quantum dot synthesis: evaluation of the structural and photoluminescent properties. Nanoscale 5:9156-9161

Thakor AS, Gambhir SS (2013) Nanooncolgy: the future of cancer diagnosis and therapy. Cancer J Clin 63:395-418

Topoglidis E, Cass AEG, O'Regan B, Durrant JR (2001) Immobilisation and bioelectrochemistry of proteins on nanoporous $\mathrm{TiO}_{2}$ and $\mathrm{ZnO}$ films. J Electroanal Chem 517:20-27

Tsay JM, Trzoss M, Shi L, Kong X, Selke M, Jung ME, Weiss S (2007) Singlet oxygen production by peptide-coated quantum dot-sensitizer conjugates. J Am Chem Soc 129:6865-6871

Tuncel S, Domoulin F, Gailer J, Sooriyaarachchi M, Atila D, Durmus M, Bouchu D, Savoie H, Boyle RW, Ahsen V (2011) A set of highly water-soluble tetraethyleneglycol- 
substituted Zn(II) phthalocyanines: synthesis, photochemical and photophysical properties, interaction with plasma proteins and in vitro phototoxicity. Dalton Trans 40:4067-4079

Vreeke M, Maidan R, Heller A (1992) Hydrogen peroxide and beta-nicotinamide adenine dinucleotide sensing amperometric electrodes based on electrical connection of horseradish peroxidase redox centers to electrodes through a three-dimensional electron relaying polymer network. Anal Chem 64:3084-3090

Xia L, Song J, Xu R, Liu D, Dong B, Xu L, Song H (2014) Zinc oxide inverse opal electrodes modified by glucose oxidase for electrochemical and photoelectrochemical biosensor. Biosens Bioelectron 59:350-357

Xiao L, Gu L, Howell SB, Sailor MJ (2011) Porous silicon nanoparticle photosensitizers for singlet oxygen and their phototoxicity against cancer cells. ACS Nano 5:3651-3659
Zhang W, Li Y, Zhang H, Zhou X, Zhong X (2011) Facile synthesis of highly luminescent $\mathrm{Mn}$-doped $\mathrm{ZnS}$ nanocrystals. Inorg Chem 50:10432-10438

Zhou K, Zhu Y, Yang X, Luo J, Li C, Luan S (2010) A novel hydrogen peroxide biosensor based on Au graphene-HRPchitosan biocomposites. Electrochim Acta 55:3055-3060

Zhou Y, Chen H, Ogawa N, Lin J (2011) Chemiluminescence from $\mathrm{NaClO}-\mathrm{H}_{2} \mathrm{O}_{2}$ and enhanced by 1 cysteine capped Mndoped ZnS quantum-dots. J Lumin 131:1991-1997

Zhuang J, Zhang X, Wang G, Li D, Yang W, Li T (2003) Synthesis of water-soluble $\mathrm{ZnS}: \mathrm{Mn}^{2+}$ nanocrystals by using mercaptopropionic acid as stabilizer. J Mater Chem 13:1853-1857 